\title{
ПОЛУЧЕНИЕ РЕКОМБИНАНТНОГО ШТАММА НЕRPESVIRUS SAIMIRI ПУTЕМ СОВМЕСТНОЙ КУЛЬТИВАЦИИ ТРАНСФИЦИРОВАННОЙ И ПЕРМИССИВНОЙ КЛЕТОЧНЫХ КУЛЬТУР
}

\author{
А. Хамад 1 , С. П. Чумаков ${ }^{2}$ \\ ${ }^{1}$ Московский физико-технический институт, Москва, Россия \\ 2 Институт биоорганической химии имени М. М. Шемякина и Ю. А. Овчинникова, Москва, Россия
}

\begin{abstract}
Рекомбинантные герпесвирусы можно применять в качестве терапевтических агентов-онколитиков, а также в качестве векторов большой емкости для доставки протяженных экспрессионных конструкций в клетки. Гамма-герпесвирус беличьих обезьян Herpesvirus saimiri обладает уникальной способностью инфицировать человеческие лимфоциты и вызывать их иммортализацию при сохранении зрелого фенотипа и функциональной активности. Проведение рекомбинации генома Herpesvirus saimiri в пермиссивной клеточной культуре затруднено из-за ее устойчивости к химической трансфекции и электропорации. Целью работы являлась разработка эффективного способа введения экспрессионных кассет в геном Неrреsvirus saimiri без проведения трансфекции пермиссивной клеточной культуры. Для этого мы использовали совместную культивацию транссицированных клеток HEK-293Т, экспрессирующих также гликопротеины вакцинного штамма вируса кори, и инфицированных Неrреsvirus saimiri пермиссивных клеток линии ОМК. Слияние клеток и образование синцитиев привели к запуску рекомбинации между вирусным геномом и экспрессионной кассетой что позволило получить рекомбинантный вариант Herpesvirus saimiri без необходимости проведения химической транссекции пермиссивных клеток. Трансгенный вариант вируса характеризовался стабильной экспрессией селективного маркера и сохранял способность персистировать в клеточной культуре в латентной форме, а также вызывать иммортализацию первичных лимфоидных клеток. Примененный метод позволяет в короткие сроки получать рекомбинантные варианты Herpesvirus saimiri с введенными в геном разнообразными экспрессионными кассетами.
\end{abstract}

Ключевые слова: герпесвирус, вирусный вектор, рекомбинантный штамм, химерный антигенный рецептор, ХАР

Финансирование: работа выполнена при финансовой поддержке Министерства образования и науки РФ (уникальный код проекта RFMEFI60418X0205).

Благодарности: авторы признательны Центру высокоточного редактирования и генетических технологий для биомедицины (Москва) за помощь в методах исследования.

Информация о вкладе авторов: А. Хамад - работа с клеточными культурами, молекулярное клонирование; С. П. Чумаков - планирование исследования, работа с вирусными препаратами, трансфекция, титрование, анализ данных и подготовка рукописи.

$\bowtie$ Для корреспонденции: Степан Петрович Чумаков

ул. Миклухо-Маклая, 16/10, г. Москва, 117997; hathkul@gmail.com

Статья получена: 11.11.2019 Статья принята к печати: 25.11.2019 Опубликована онлайн: 11.12.2019

DOI: $10.24075 /$ vrgmu.2019.079

\section{ENGINEERING A RECOMBINANT HERPESVIRUS SAIMIRI STRAIN BY CO-CULTURING TRANSFECTED AND PERMISSIVE CELLS}

Hamad $\mathrm{A}^{1}$, Chumakov SP${ }^{2 \otimes}$

${ }^{1}$ Moscow Institute of Physics and Technology, Moscow, Russia

2 Shemyakin-Ovchinnikov Institute of Bioorganic Chemistry of the Russian Academy of Sciences, Moscow, Russia

Recombinant herpesviruses can be used as oncolytic therapeutic agents and high packaging capacity vectors for delivering expression cassettes into the cell. Herpesvirus saimiri is a gamma-herpesvirus that normally infects squirrel monkeys but also has a unique ability to infect and immortalize human lymphocytes while allowing them to retain their mature phenotype and functional activity. Recombination of the Herpesvirus saimiri genome in permissive cells is impeded by its resistance to chemical transfection and electroporation. The aim of this study was to develop an effective method for incorporating expression cassettes into the genome of Herpesvirus saimiri without having to transfect a permissive cell culture. Transfected HEK-293T cells expressing glycoproteins of the measles virus vaccine strain were co-cultured with permissive OMK cells infected with Herpesvirus saimiri. Cell fusion and formation of syncytia stimulated recombination between the viral genome and the expression cassette; this allowed us to obtain a recombinant Herpesvirus saimiri variant without chemical transfection in permissive cells. The genetically modified virus expressed a selectable marker and retained its ability to persist in the cell in the latent state; it also caused immortalization of primary lymphoid cells. The proposed approach allows engineering recombinant Herpesvirus saimiri strains carrying a variety of expression cassettes in its genome.

Keywords: herpesvirus, viral vector, recombinant strain, chimeric antigen receptor, CAR

Funding: this study was supported by the Ministry of Science and Higher Education of the Russian Federation (Project ID RFMEFI60418X0205).

Acknowledgement: we thank to the Center for Precision Genome Editing and Genetic Technologies for Biomedicine (Moscow) for the genetic research methods.

Author contribution: Hamad A - manipulations on cell cultures, molecular cloning; Chumakov SP — study plan; manipulations on viral stocks, transfection, titration, data analysis, manuscript preparation.

$\triangle$ Correspondence should be addressed: Stepan P. Chumakov Miklouho-Maclay, 16/10, Moscow, 117997; hathkul@gmail.com

Received: 11.11.2019 Accepted: 25.11.2019 Published online: 11.12.2019

DOI: 10.24075/brsmu.2019.079

Герпесвирусы - большое семейство ДНК-содержащих вирусов, которые поражают человека и животных. Вирусы обладают протяженным геномом, кодирующим около 100200 генов, чья репликация происходит в ядре зараженной клетки. Сборка и выход новых вирусных частиц из клеток сопровождаются цитолизом. Особенностью вирусов семейства является способность к существованию в латентной форме. Полноразмерный геном герпесвируса при этом сохраняется в ядре клетки в форме эписом, реплицирующихся с той же скоростью, что и геном клетки- 
хозяина, и распределяющихся между дочерними клетками в процессе деления за счет ассоциации с центромерными участками хроматид. Латентная форма существования герпесвирусов сопровождается экспрессией небольшого числа специализированных генов и протекает бессимптомно [1]. Представители подсемейства гаммагерпесвирусов, обладающие тропизмом к лимфоидным клеткам, нередко обладают онкогенными свойствами: вирус Эпшнейна-Барр (ВЭБ) [2] и вирус саркомы Капоши (BCK) [3] ассоциированы с лимфопролиферативными заболеваниями, в частности В-клеточными неоплазиями. ВЭБ часто является причиной спонтанной иммортализации В-клеток, полученных из крови здоровых людей [4].

Филогенетический родственник ВCK, гаммагерпесвирус из подсемейства радиновирусов Herpesvirus saimiri (HVS) поражает беличьих обезьянок Нового света. Инфекция чаще всего протекает бессимптомно, и большинство обезьян этого вида являются латентными носителями вируса. Примечательно, что заражение этим вирусом других видов обезьян Нового света приводит к стремительному развитию Т-клеточных лейкозов и быстрой гибели животных. В опытах с мононуклеарными клетками животных было показано, что вирус способен вызывать спонтанную иммортализацию Т-лимсоцитов [5]. Такое же действие обнаружено и при инфицировании штаммами C HVS человеческих лимфоцитов и натуральных киллеров [6]. Клетки приобретали способность к неограниченной IL2-зависимой пролиферации, не теряя фенотипических признаков зрелых Т-лимфоцитов и натуральных киллеров [7]. Экспрессия сохранялась у трех вирусных генов: ассоциированных с трансформацией STP и TIP [8], а также у ORF73 [9] - гомолога ассоциированного с латентностью антигена (LANA) BCK, который необходим для распределения эписом между дочерними клетками в процессе митоза [10]. Геном вируса оставался в них в латентной форме, а попытки вызвать развитие литической инфекции либо иным способом зафиксировать появление вирулентных частиц в культурах иммортализованных лимфоидных клеток человека или обезьян Старого света оканчивались неудачей. В опытах на макаках было показано, что аутологичная реинфузия Т-лимфоцитов, иммортализованных наиболее агрессивным штаммом HVS C488, не приводит к развитию неоплазий. Вирусная ДНК могла быть обнаружена в образцах периферических мононуклеаров животных в течение как минимум 16 недель, а сами животные приобретали иммунитет к инфекции HVS [11].

Для создания модифицированных вариантов герпесвирусов, способных выступать в качестве векторов для экспрессии трансгенов, была успешно использована гомологичная рекомбинация участков вирусного генома в пермиссивных клеточных культурах, а также рекомбинирование в бактериальных хромосомах (bacterial artificial chromosome, BAC) [12]. В бактериальную хромосому клонировали геном HVS штамма A11-S4. Геном HVS содержит несколько гомологов клеточных генов, большинство из которых встречаются и у других вирусов подсемейства. В отличие от остальных, ген vCD59 не встречается в геноме других гамма-герпесвирусов, а рецептор, последовательность которого он кодирует, отвечает за подавление опосредованной комплементом цитотоксичности [13]. Этот ген экспрессируется только в литической фазе и не нужен для наработки вирусных частиц в условиях in vitro. В работах, посвященных созданию векторов на основе HVS, последовательность vCD59 успешно замещали экспрессионными кассетами [14].
Совокупность имеющихся данных позволяет сделать предположение, что HVS можно использовать для создания новых клеточных иммунотерапевтических агентов [15]. HVSтрансформированные Т-лимфоциты и НК-клетки сохраняют свои эффекторные функции и могут быть таргентированы против опухолевых антигенов за счет экспрессии химерных рецепторов. Основное преимущество такого подхода в возможности получения неограниченного количества эффекторных клеток из относительно небольших обьемов периферической крови пациента либо проведения аллогенных трансплантаций клеточных препаратов. Большой размер генома HVS и его высокая емкость как вектора [14] делают возможным проведение иммортализации и трансдукции экспрессионной кассетой в один этап. Целью настоящей работы было создание быстрого способа получения рекомбинантных вариантов HVS на основе штамма C488, которые могут быть использованы для введения в геном вируса разнообразных трансгенов.

\section{МАТЕРИАЛЫ И МЕТОДЫ}

\section{Культивирование клеток и наработка вирусных препаратов}

Использованные в работе линии клеток НЕК-293Т (культура человеческих трансформированных клеток), ОМК (культура клеток почки ночной обезьяны Aotus trivirgatus), A549 (культура клеток легочной карциномы) были получены из Американской коллекции типовых клеточных культур (АТСС; США). Их культивировали в среде DMEM-F12 (РAA; Австрия), в которую добавляли 10\%-ю эмбриональную сыворотку теленка, 2 мМ аланилглутамина (ПанЭко; Россия), 20 мМ HEPES и по 100 мкг/мл пенициллина и стрептомицина (ПанЭко; Россия).

Периферические мононуклеарные клетки (РВМС) культивировали в среде RPMI-1640 (РAA; Австрия) с добавлением 10\%-й эмбриональной сыворотки теленка, 2 мМ аланилглутамина (ПанЭко; Россия), 20 мМ HEPES и по 100 мкг/мл пенициллина и стрептомицина, а также 70 нг/мл IL2 (Peprotech; CШA). Все клетки содержали в условиях 5\%-го $\mathrm{CO}_{2}$ при $37^{\circ} \mathrm{C}$.

Вирус штамма HVS-C488 (VR-1414) был получен из ATCC. Для наработки вирусных препаратов субконфлюэнтную культуру клеток линии ОМК заражали небольшим количеством вируса $(\mathrm{MOI}<0,1)$ и культивировали в соответствующей питательной среде в течение 5-15 дней до наступления полного цитолиза. Затем собирали вируссодержащую жидкость и центрифугировали 15 мин при 5000 g на центрифуге Eppendorf 5920R (Eppendorf; ФРГ) для удаления клеточного дебриса. Собирали супернатант, разделяли на рабочие порции и хранили при $-20{ }^{\circ} \mathrm{C}$.

\section{Плазмидные конструкции}

Плазмиды с экспрессорами поверхностных гликопротеинов кори pCG-4AHc $\triangle 24$ и pMD2-F $\triangle 30$ были получены ранее. Для введения в геном HVS экспрессионной кассеты создали конструкцию pUC-HVS-OFP. Участок вирусного генома, кодирующий vCD59, использовали как сайт для проведения рекомбинации. В качестве гомологичных участков были выбраны 600-нуклеотидные последовательности, соответствующие 3'- и 5'-концам vCD59. Фрагменты ДНК получали при помощи ПЦР с использованием в качестве матрицы ДНК, выделенной из концентрированного препарата HVS. Между 
фланкирующими участками в экспрессионную кассету был помещен промотор вируса некроза селезенки мышей (SFFV) и последовательности генов устойчивости К пуромицину (рас) и оранжевого флуоресцентного белка (ОFР), экспрессируемые полицистронно за счет помещенной между ними последовательности сигнального пептида Т2А. Последовательность, состоящая из фланкирующих участков по 600 п.н. каждый, гомологичных области vCD59 генома HVS, и расположенной между ними экспрессионной кассеты, клонировали в плазмидуноситель pUC18 (рис. 1) по рестриктным сайтам Notl и BamHI. Клонируемый фрагмент собрали из трех частей методом перекрывающего ПЦР [16]. Праймеры, использованные для амплификации участков генома HVS и экспрессионной кассеты, представлены в табл. 1. Последовательности готовых конструкций и препараты ДНК рекомбинантного HVS верифицировали при помощи секвенирования по Сэнгеру (Евроген; Россия).

\section{Трансфекция}

Для определения наиболее эффективного способа трансфекции клеток линии ОМК использовали катионный полимер полиэтиленимина 25 кДА (PEI-25) (Polysciences; США), катионный липид Lipofectamine 2000 (Invitrogen; США), а также электропорацию. За сутки до проведения трансфекции клетки рассеивали на культуральные чашки диаметром 10 см (SPL; Корея) в количестве $2 \times 10^{6}$ клеток на чашку. Для трансфекции использовали либо кольцевую форму плазмиды pUC-HVS-OFP, либо линеаризованную непосредственно перед проведением трансфекции путем рестрикции по сайтам расщепления эндонуклеазами Notl и $\mathrm{BamHI}$. Для трансфекции с помощью PEI-25 использовали описанные ранее условия и буферы [17]: плазмидную ДНК смешивали с PEI-25 (5 мкг/Мкл) в соотношении 6: 1 в лактатном буффере с рН 4, смесь инкубировали в течение 15 мин, после чего добавляли среду OptiMEM (Invitrogen; США) и вносили в культуральную среду на чашки с клетками. Для определения оптимальных условий трансфекции проводили трансфекцию с 3, 5, 10, 15 и
20 мкг кольцевой плазмиды, либо с 1, 3, 5, 10 или 15 мкг линеаризованной плазмиды. Трансфекцию при помощи катионного липида Lipofectamine 2000 (Invitrogen; США) проводили в соответствии с рекомендациями производителя; использовали по 7, 10 и 15 мкГ плазмидной ДНК в кольцевой либо линеаризованной форме и 17,5, 25 и 37,5 мкл реагента соответственно. Через 3 ч после постановки трансфекции обоими методами проводили смену среды на обычную, используемую для культивации клеток ОМК. Для проведения электропорации клетки открепляли от чашек при помощи раствора TrypLE (Gibco; CША), центрифугировали при 1100 об./мин в течение 5 мин на центрифуге Eppendorf 5702 (Eppendorf; ФРГ), осажденные клетки ресуспендировали в 500 мкл фоссатно-солевого буфера. Саму электропорацию проводили при помощи электропоратора GenePulser (Bio-Rad; США) в кюветах с межэлектродным расстоянием 4 мм, с параметрами 300 v / 500 uF, либо 200 v / 250 uF, перед электропорацией к клеткам добавляли по 5 либо 10 мкг кольцевой или линейной плазмидной ДНК. После электропорации клетки немедленно высеивали чашки диаметром 10 см с добавлением 10 мл полной питательной среды. Через 48 ч после постановки трансфекции, долю трансфицированных клеток измеряли на проточном цитометре FacsVantage SE (Beckton-Dickinson; США). Оценку жизнеспособности клеточных культур производили путем подсчета клеток в образцах после их открепления при помощи TrypLE и окрашивания раствором трипанового синего (Панэко; Россия) при помощи Cytosmart Cell Counter (Corning; США).

Трансфекцию проводили на 6-луночных планшетах в среде для культивирования ОрtiMEM с использованием PEI-25 на клетках HEK-293T в плотности 40-60\% от монослоя, рассеянных накануне. Использовали плазмиды pUC-HVS-OFP, содержащие экспрессионную кассету, фрланкированную гомологичными участками из генома HVS, и плазмиды, экспрессирующие поверхностные гликопротеины F (от англ. fuion protein - белок слияния) и Н (от англ. haemagglutinin - гемагглютинин) вакцинного штамма (ЭШЧ) вируса кори. Для экспрессии белков $\mathrm{F}$ и H использовали плазмиды pMD2-F $\Delta 30$ и pCG-4AHc $\Delta 24$ соответственно;

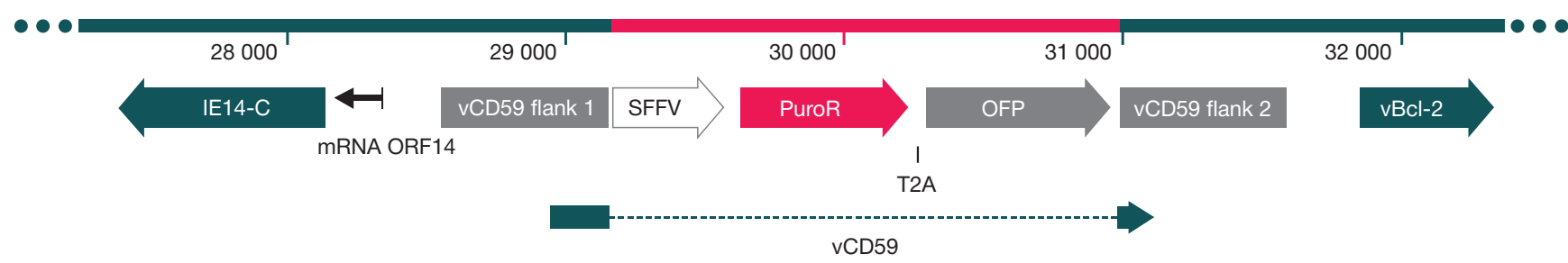

Pис. 1. Схематичная организация участка генома HVS в области гена vCD59 после интеграции экспрессионной кассеты. «VCD59 flank 1» и "vCD59 flank 2" - области генома, использованные в качестве учасктов гомологии для рекомбинации

Таблица 1. Последовательности праймеров, использовавшиеся для сборки экспрессионной кассеты

\begin{tabular}{|l|l|}
\hline \multicolumn{1}{|c|}{ Название } & \multicolumn{1}{|c|}{ Нуклеотидная последовательность } \\
\hline vCD59 F1 dir & AGAGAGGCGGCCGCACAGGCTGCTCTTCAGGAGCACCAG \\
\hline vCD59 F1 rev & CAATTGATTGGGATGCGTTTGAGC \\
\hline vCD59 F1 bridge & GCAAATGGCGTTACCTCGAGCAATTGATTTGAGATGCGTTTGAAGC \\
\hline SFFV dir & CTCGAGGTAACGCCATTTTGC \\
\hline OFP rev & CCTGCAGGTCAAGCTTCGAA \\
\hline vCD59 F2 bridge & TTCGAAGCTTGACCTGCAGGTCTGAAACACAGTTAAAGTATCATTGTTG \\
\hline vCD59 F2 dir & TCTGAAACACAGTTAAAGTATCATTGTTG \\
\hline vCD59 F2 BamHI rev & TCTCTCGGATCCGCTGGCAGATATTTCTTTTATAAACAGG \\
\hline vCD59 F1 diag dir & GCACAGGCTGCTCTTCAGGAGCACCAG \\
\hline vCD59 F2 diag rev & GCTGGCAGATATTTCTTTTATAAACAGG \\
\hline
\end{tabular}


pMD2-FA30 кодировала последовательность белка F c укороченным на 30 аминокислотных остатков С-концевым цитоплазматическим доменом, а pCG-4AHc $\triangle 24$ кодировала последовательность белка Н, в которой первые 24 аминокислоты N-концевого цитоплазматического домена были замещены четырьмя остатками аланина, белки экспрессировались под контролем цитомегаловирусного промотора. При проведении котрансфекции плазмиды pUC-HVS-OFP, pMD2-F 330 и pCG-4AHc $\triangle 24$ смешивали в соотношении $8: 7: 1$ соответственно. После трехчасовой инкубации клеток с трансфекционной смесью клетки диссоциировали раствором трипсина (ПанЭко; Россия) и культивировали совместно с инфицированными HVS-C488 клетками линии ОМК в соотношениях, представленных в табл. 2.

\section{Титрование и клонирование вирусных препаратов}

Для определения инфекционного титра вируса осуществляли инфекцию последовательными пятикратными разведениями вирусного препарата клеток ОМК в 96-луночных планшетах (Greiner; Австрия) в четырех повторностях. После наступления цитопатического действия (ЦПД) рассчитывали инфекционный титр методом Рида-Менча. Для клонирования рекомбинантного HVSOFP на лунки 96-луночного планшета, в которые за 24 ч до этого были рассеяны свежие клетки линии ОМК в субкофлюэнтном количестве, добавляли культуральную среду, содержащую предварительно отсортированные на проточном клеточном сортировщике FacsVantage SE (Beckton-Dickinson; США) инфицированные флуоресцирующие клетки ОМК в известной концентрации, из расчета 10, 1, 0,1 и 0,01 инфицированной клетки на лунку. Через 5-7 дней в лунках определяли наличие единичных флуоресцирующих фокальных очагов ЦПД.

\section{Определение рекомбинантов}

Для подтверждения события рекомбинации клонированные препараты HVS-OFP концентрировали при помощи центрифужных концентраторов Amicon Ultra 3 kDa (Merck; Германия), после чего определяли наличие целевой вставки в геноме HVS при помощи ПЦР с праймерами vCD59 F1 diag dir и vCD59 F2 diag rev. Продукт реакции длиной 3000 п.н. указывал на присутствие целевой вставки, а длиной 1200 п.н. — на вирус «дикого» фенотипа.

\section{Статистический анализ}

Статистическую обработку результатов экспериментов проводили с помощью пакета статистических программ Prism 6.0 (GraphPad Software; CШA).

\section{РЕЗУЛЬТАТЫ ИССЛЕДОВАНИЯ}

Для проведения рекомбинации и получения трансгенного варианта HVS-C488 была создана экспрессионная кассета, содержащая два селективных маркера ген оранжевого флуоресцентного белка OFP и ген устойчивости к пуромицину, кодирующий пуромицин-Nацетилтранссреразу (Рас). Поиск оптимальных условий трансфекции вируспермиссивных клеток линии ОМК показал, что наибольшей эффективности можно добиться при использовании PEI-25 и линейного фрагмента экспрессионной кассеты (соотношение PЕІ : ДНК составляет 6 : 1; 10 мкг ДНК на $2 \times 10^{6}$ клеток; табл. 3), однако доля трансфицированных клеток не превышала $5 \%$ от общей численности популяции (рис. 2). Увеличение количества ДНК и трансфекционного агента приводило к сильному снижению жизнеспособности клеточной культуры; при использовании электропорации снижения жизнеспособности не наблюдалось, однако доля трансфицированных клеток оставалась крайне малой. Чтобы оценить, может ли трансфекция с максимальной достигнутой эффективностью приводить к образованию рекомбинантных вирусных частиц, вызывающих экспрессию селективных маркеров в инфицированных клетках, мы собрали осветленные вируссодержащие культуральные жидкости с предварительно инсицированных HVS-C488 клеток линии OMК, которые были трансфицированы при помощи PEI-25 и линейного фрагмента экспрессионной кассеты. Культуральные жидкости были использованы для инфицирования свежих ОМК, последующее наблюдение за которыми не выявило наличия клеток, экспрессирующих фрлуоресцентный маркер.

Чтобы повысить вероятность рекомбинации HVS и экспрессионной кассеты, был разработан альтернативный способ доставки модифицированной ДНК в пермиссивные клетки. Мы предположили, что способность поддерживать литический цикл развития вируса у клеток линии ОМК сохранится после слияния с некоторым количеством непермиссивных клеток НЕК-293Т, которые непосредственно перед этим могут быть трансфицированы экспрессионной кассетой. Для проведения рекомбинации в смешанной клеточной системе клетки линии НЕК-293Т трансфицировали линеаризованной экспрессионной кассетой либо нелинеаризованной плазмидой, ее содержащей, совместно с плазмидами, кодирующими поверхностные гликопротеины вакцинного штамма вируса кори (белки F и Н с укороченными цитоплазматическими доменами), появление которых на клеточной мембране вызывает слияние контактирующих клеток в синцитии за счет связывания с рецептором CD46 (рис. ЗГ, Д). Через 3 ч после трансфекции клетки переводили в суспензию и рассеивали на лунки совместно с клетками ОМК, которые

Таблица 2. Количества клеток и их соотношения, использованные при совместной культивации, и инсекционный вирусный титр, засиксированный в супернатантах

\begin{tabular}{|c|c|c|c|c|}
\hline № & OMК (тыс.) & НЕК-293Т (тыс.) & Соотношение & Вирусный титр \\
\hline 1 & 450 & 1333 & 0,34 & $1,60 \mathrm{E}+03$ \\
\hline 2 & 100 & 1333 & 0,08 & $8,00 \mathrm{E}+02$ \\
\hline 3 & 23 & 1333 & 0,02 & 0 \\
\hline 4 & 68 & 200 & 0,34 & $2,56 \mathrm{E}+04$ \\
\hline 5 & 27 & 200 & 0,14 & $1,28 \mathrm{E}+04$ \\
\hline 6 & 10 & 200 & 0,05 & 0 \\
\hline 7 & 450 & 133 & 3,38 & $2,56 \mathrm{E}+04$ \\
\hline 8 & 225 & 266 & 0,85 & $2,56 \mathrm{E}+04$ \\
\hline
\end{tabular}


за 2 дня до трансфекции были заражены HVS-C488 $(\mathrm{MOI}=4)$ в различных соотношениях и плотностях посадки (см. табл. 2).

Через 4 дня после начала совместной культивации с клеток собирали вируссодержащий супернатант и определяли инфекционный титр вируса. После сравнения концентраций инфекционных частиц образец № 5 был выбран в качестве оптимального для селекции моноклонального рекомбинантного вируса, поскольку в нем зафиксировали максимальный инфекционный титр относительно общего содержания вируспермиссивных клеток и их соотношения с клетками HEK-293Т.

Вируссодержащую среду, собранную с образца № 5, использовали для инфицирования ОМK (MOI = 0,01), через 7 дней в конфлюэнтной клеточной культуре начали образовываться фокальные участки развития цитолитической инфекции, среди которых были обнаружены отдельные бляшки, сформированные преимущественно фллуоресцентными клетками (рис. ЗБ). Популяцию флуоресцирующих клеток отсортировали и использовали для инфицирования пермиссивных клеток на 96-луночном планшете из расчета 10, 1, 0,1 и 0,01 инфицированных клеток на лунку. Через 10 дней после инфицирования в образцах, подвергшихся заражению с множественностью 0,1 клеток на лунку были зафиксированы 3 (из 96) единичные флуоресцентные бляшки, образованные, по-видимому, индивидуальными рекомбинировавшими вирусными частицами. Вируссодержащую среду из лунки № 2, в которой был зафиксирован наиболее активно развивающийся литический процесс, использовали для наработки препаративных количеств рекомбинантного вирусного препарата и его анализа.
Секвенирование участка vCD59 ДНК препарата рекомбинантного герпесвируса HVS-OFP показало наличие в нем целевой экспрессионной кассеты. Трансдукция периферических мононуклеарных клеток и клеток линии A549 вирусом HVS-OFP $(\mathrm{MOI}=5)$ привела к образованию фракций флуоресцирующих клеток (рис. 3В, Г); для линии A549 их доля сохранялась постоянной в течение 5 недель после инфицциования, а для РВМС - постоянно увеличивалась (рис. ЗА). Эти данные позволяют сделать вывод о том, что полученный рекомбинантный вариант герпесвируса HVS-OFP не утратил способности находиться в клетках в латентной форме и вызывать иммортализацию нормальных лимфоидных клеток. Экспрессия введенной кассеты при этом сохраняется как в литической, так и в латентной фазе существования герпесвируса.

\section{ОБСУЖДЕНИЕ РЕЗУЛЬТАТОВ}

В данном исследовании был разработан и успешно испытан новый подход для генетической инженерии герпесвирусов методом рекомбинации. Использование экспрессионной кассеты, содержащей два селективных маркера, было обусловлено результатами испытания разных способов повышения вероятности прохождения рекомбинации предполагалось, что проведение селекции с пуромицином либо сортировки фрлуоресцентных ОМК непосредственно после трансфекции позволит удалить из популяции нетрансфицированные клетки. Попытки реализовать такую схему селекции показали, что времени, проходящего с момента введения экспрессионной кассеты до проявления цитопатического действия и выхода вируса в среду, недостаточно для селекции с помощью пуромицина, а

Таблица 3. Условия трансдукции пермиссивных клеток линии OMK экспрессионной кассетой для рекомбинации HVS и достигнутые значения эффективности

\begin{tabular}{|c|c|c|c|}
\hline Метод трансдукции & Условия & Доля трансдуцированных клеток & Снижение жизнеспособности \\
\hline \multirow{10}{*}{ PEI-25 } & 3 мкг кольцевой ДНК & $0,7 \% \pm 0,15 \%$ & - \\
\hline & 5 мкг кольцевой ДНК & $1,82 \% \pm 0,15 \%$ & - \\
\hline & 10 мкг кольцевой ДНК & $3,73 \% \pm 0,15 \%$ & $+/-$ \\
\hline & 15 мкг кольцевой ДНК & $3,13 \% \pm 0,15 \%$ & + \\
\hline & 20 мкг кольцевой ДНК & $1,77 \% \pm 0,15 \%$ & + \\
\hline & 1 мкг линейной ДНК & $<0,15 \% \pm 0,15 \%$ & - \\
\hline & З мкг линейной ДНК & $0,85 \% \pm 0,15 \%$ & - \\
\hline & 5 мкг линейной ДНК & $1,91 \% \pm 0,15 \%$ & - \\
\hline & 10 мкг линейной ДНК & $4,76 \% \pm 0,15 \%$ & $+/-$ \\
\hline & 15 мкг линейной ДНК & $3,2 \% \pm 0,15 \%$ & + \\
\hline \multirow{6}{*}{ Lipofectamine 2000} & 7 мкг кольцевой ДНК & $3,11 \% \pm 0,15 \%$ & - \\
\hline & 10 мкг кольцевой ДНК & $4,11 \% \pm 0,15 \%$ & - \\
\hline & 15 мкг кольцевой ДНК & $4,09 \% \pm 0,15 \%$ & + \\
\hline & 7 мкг линейной ДНК & $3,18 \% \pm 0,15 \%$ & - \\
\hline & 10 мкг линейной ДНК & $4,63 \% \pm 0,15 \%$ & - \\
\hline & 15 мкг линейной ДНК & $4,54 \% \pm 0,15 \%$ & + \\
\hline \multirow{8}{*}{ Электропорация } & 5 мкг кольцевой ДНК, 200V/250uF & $<0,15 \% \pm 0,15 \%$ & - \\
\hline & 10 мкг кольцевой ДНК, 200V/250uF & $<0,15 \% \pm 0,15 \%$ & - \\
\hline & 5 мкг линейной ДНК, 200V/250uF & $<0,15 \% \pm 0,15 \%$ & - \\
\hline & 10 мкг линейной ДНК, 200V/250uF & $<0,15 \% \pm 0,15 \%$ & - \\
\hline & 5 мкг кольцевой ДНК, 300V/500uF & $<0,15 \% \pm 0,15 \%$ & - \\
\hline & 10 мкг кольцевой ДНК, 300V/500uF & $<0,15 \% \pm 0,15 \%$ & - \\
\hline & 5 мкг линейной ДНК, 300V/500uF & $<0,15 \% \pm 0,15 \%$ & - \\
\hline & 10 мкг линейной ДНК, 300V/500uF & $<0,15 \% \pm 0,15 \%$ & - \\
\hline
\end{tabular}


стресс, сопутствующий флуоресцентной сортировке трансдуцированных клеток, приводит к подавлению продукции вируса. Вместе с тем, наличие двух селективных маркеров позволяет с большим удобством проводить отбор и мониторинг доли клеточной популяции, трансдуцированной рекомбинантным HVS. Применительно к использованному вирусному штамму HVS-C488 разработанный подход позволяет обойти главное препятствие - низкую эффективность трансфекции пермиссивной клеточной популяции трансгенной кассетой
[18], в то время как для других описанных на настоящий момент методик рекомбинации HVS этот этап является ключевым [15, 19]. Эфффективность прохождения рекомбинации зависит от длины рекомбинируемого участка, поэтому введение экспрессоров нескольких генов с большой общей протяженностью потребует либо нескольких последовательных стадий рекомбинирования, либо масштабирования трансфекции и селекции на большее количество клеток. При выполнении подобных задач разработанный метод уступает по своей эффективности

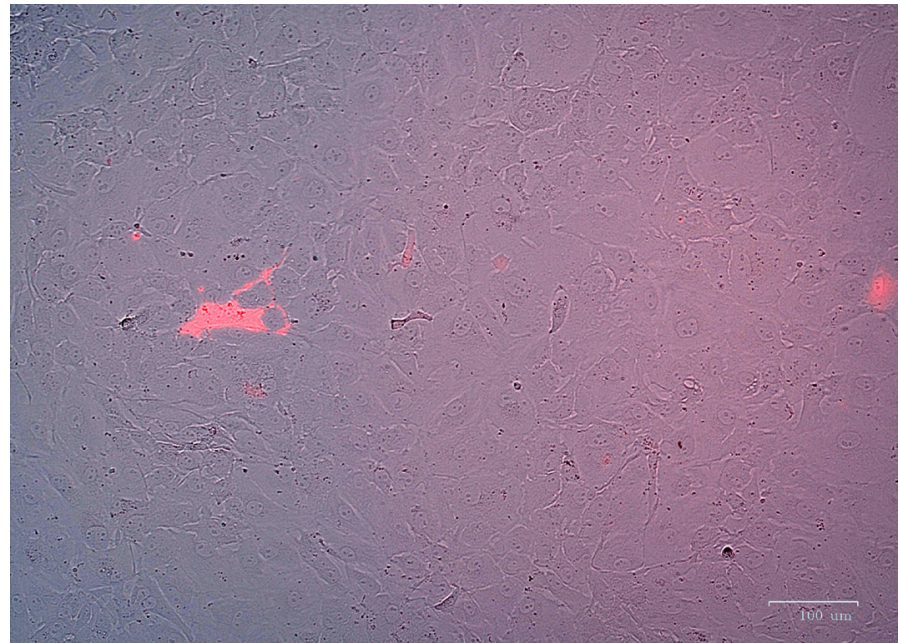

Pис. 2. Популяция вируспермиссивных клеток линии ОМК, трансдуцированных экспрессионной кассетой SFFV-PURO-OFP

A

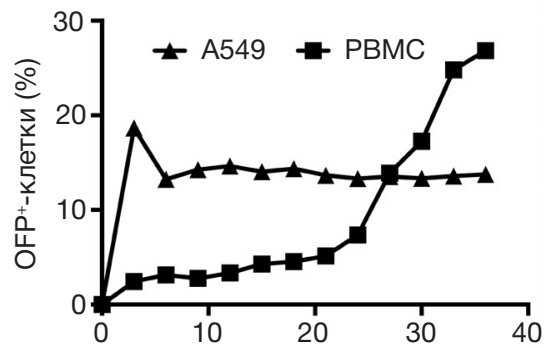

Время после инфицирования (дни)

B



Д



Б

$\Gamma$
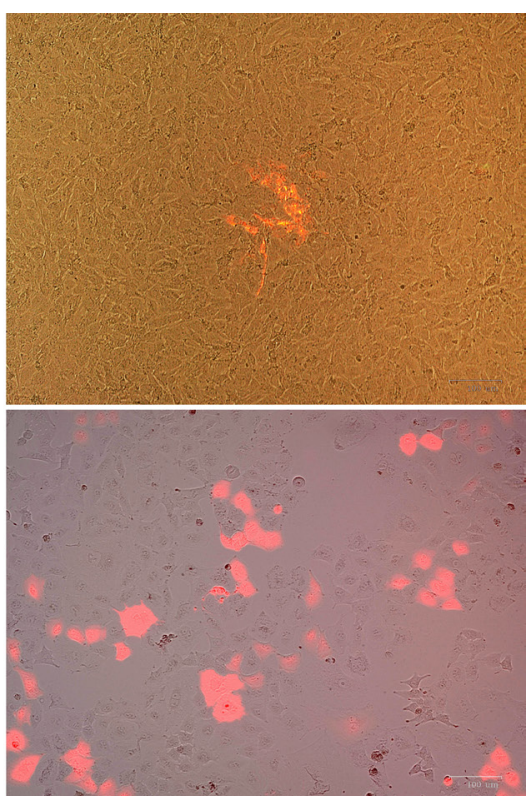

$\mathrm{E}$

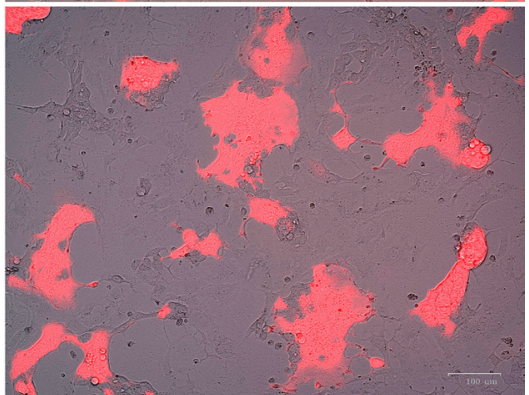

Рис. 3. А. Динамика изменения численности флуоресцентных популяций после инфицирования HVS-OFP. Б. Флуоресцентная бляшка, образованная при инфицировании рекомбинантным HVS-OFP культуры клеток OMК. В. Г. РВMC (В) и A549 (Г), трансдуцированные HVS-OFP. Д. Е. Совместная культивация трансфицированных рекомбинантной кассетой и экспрессорами гликопротеинов вакцинного штамма кори НЕК-293Т и инфицированных HVS OMK в низкой (Д) и высокой (Е) плотностях 
методам рекомбинирования в бактериальной хромосоме, которые показали свою эффективность, в том числе при манипулировании геномом HVS [20, 21]. Хотя рекомбинирование в эукариотической системе в целом отличается большей трудоемкостью, чем проведение аналогичных манипуляций в бактериальной хромосоме, этот метод может быть предпочтительным, когда требуется создание единичных трансгенных вариантов, либо для поготовки вирусного генома к клонированию в ВАС, например добавления селективной кассеты для облегчения рекомбиниринга. Такое применение представляется нам особенно интересным в связи с тем, что геном штамма С488, который способен с наибольшей эффективностью вызывать трансформацию человеческих Т-лимфоцитов и натуральных киллеров [22], пока не был клонирован в ВАС.

В перспективе разработанный метод может позволить получать химерные вирусные частицы, лишенные генов, необходимых при развитии литической инфекции, и пригодные для препаративного получения иммортализованных лимфоидных клеток с целью проведения иммунотерапии. Стоит отметить, что большая клонирующая емкость герпесвирусного вектора [23] позволяет использовать его для одновременной доставки практически всего инструментария CAR-T клеточной терапии - моно- и биспецифичных химерных антигенных рецепторов либо даже их полноразмерных пар для точного нацеливания на специфический фенотип опухолевых клеток; средств подавления экспрессии рецепторов иммунных контрольных точек для снижения чувствительности к иммуносупрессивным сигналам; индуцируемых экспрессионных кассет для секреции цитокинов, стимулирующих опухолевое микроокружение, а

\section{Литература}

1. Davison AJ. Overview of classification. In: Anvin A, Campadelli-Fiume G, Mocarski E, Moore PS, Roizman B, Whitley R, et al., editors. Human Herpesviruses: Biology, Therapy and Immunoprophylaxis. Cambridge, 2007

2. Javier RT, Butel JS. The history of tumor virology. Cancer Res. 2008; 68 (19): 7693-706. DOI: 10.1158/0008-5472.CAN-083301. PubMed PMID: 18829521.

3. Chang Y, Cesarman E, Pessin MS, Lee F, Culpepper J, Knowles DM, et al. Identification of herpesvirus-like DNA sequences in AIDSassociated Kaposi's sarcoma. Science. 1994; 266 (5192): 1865-9. DOI: 10.1126/science.7997879. PubMed PMID: 7997879.

4. Fu Z, Cannon MJ. Functional analysis of the CD4(+) T-cell response to Epstein-Barr virus: T-cell-mediated activation of resting B cells and induction of viral BZLF1 expression. J Virol. 2000; 74 (14): 6675-9. DOI: 10.1128/jvi.74.14.6675-6679.2000. PubMed PMID: 10864684.

5. Fickenscher $\mathrm{H}$, Fleckenstein B. Herpesvirus saimiri. Philos Trans R Soc Lond B Biol Sci. 2001; 356 (1408): 545-67. DOI: 10.1098/ rstb.2000.0780. PubMed PMID: 11313011.

6. Biesinger B, Muller-Fleckenstein I, Simmer B, Lang G, Wittmann S, Platzer $E$, et al. Stable growth transformation of human $T$ lymphocytes by herpesvirus saimiri. Proc Natl Acad Sci USA. 1992; 89 (7): 3116-9. DOI: 10.1073/pnas.89.7.3116. PubMed PMID: 1313581

7. Vogel B, Tennert K, Full F, Ensser A. Efficient generation of human natural killer cell lines by viral transformation. Leukemia. 2014; 28 (1): 192-5. DOI: 10.1038/leu.2013.188. PubMed PMID: 23787393.

8. Duboise SM, Guo J, Czajak S, Desrosiers RC, Jung JU. STP and Tip are essential for herpesvirus saimiri oncogenicity. J Virol. 1998; 72 (2): 1308-13. PubMed PMID: 9445031

9. Griffiths R, Whitehouse A. Herpesvirus saimiri episomal persistence также защитных механизмов, позволяющих индуцировать "самоубийство» модифицированных лимфоцитов и быстро элиминировать их из организма пациента в случае развития побочных эффектов терапии либо успешного окончания лечения. В сочетании со способностью к иммортализации периферических Т-лимфоцитов и натуральных киллеров такой вектор можно использовать в целях создания серии готовых препаратов для аллогенной клеточной иммунотерапии, которые могут быть практически неограниченно наработаны ех vivo.

\section{ВЫВОДЫ}

Использование совместной культивации трансфициированных экспрессионной кассетой и экспрессорами поверхностных гликопротеинов кори Fd30 и Hd24 в соотношении $8: 1: 7$ клеток линии НЕК-293Т и инфицированных за 48 ч до эксперимента диким вариантом HVS-C488 пермиссивных клеток линии ОМК (MOI = 4) в соотношении $27: 200$ привело к высокой частоте возникновения рекомбинантных вирусных частиц ( 3\%) и позволило за три пассажа получить готовый вирусный препарат с интегрированной экспрессионной кассетой. Полученный рекомбинантный герпесвирус HVS-OFP сохранял способность вызывать литическую инфекцию только в пермиссивных клетках линии ОМК и самоподдерживаться в латентной фазе в клетках линии А549. Вирус вызвал иммортализацию человеческих периферических мононуклеарных клеток, также сохраняясь в них в латентной форме. Введенная в геном вируса экспрессионная кассета оставалась работоспособной как в процессе литической инфекции, так и в латентной форме существования герпесвируса.

is maintained via interaction between open reading frame 73 and the cellular chromosome-associated protein MeCP2. J Virol. 2007; 81 (8): 4021-32. DOI: 10.1128/JVI.02171-06. PubMed PMID: 17267510

10. Verma SC, Robertson ES. ORF73 of herpesvirus Saimiri strain C488 tethers the viral genome to metaphase chromosomes and binds to cis-acting DNA sequences in the terminal repeats. J Virol. 2003; 77 (23): 12494-506. DOI: 10.1128/jvi.77.23.1249412506.2003. PubMed PMID: 14610173.

11. Knappe A, Feldmann G, Dittmer U, Meinl E, Nisslein T, Wittmann S, et al. Herpesvirus saimiri-transformed macaque $T$ cells are tolerated and do not cause lymphoma after autologous reinfusion. Blood. 2000; 95 (10): 3256-61. PubMed PMID: 10807797.

12. Menotti L, Avitabile E, Gatta V, Malatesta P, Petrovic B, Campadelli-Fiume G. HSV as A Platform for the Generation of Retargeted, Armed, and Reporter-Expressing Oncolytic Viruses. Viruses. 2018; 10 (7). DOI: 10.3390/v10070352. PubMed PMID: 29966356

13. Albrecht JC, Nicholas J, Biller D, Cameron KR, Biesinger B, Newman C, et al. Primary structure of the herpesvirus saimiri genome. J Virol. 1992; 66 (8): 5047-58. PubMed PMID: 1321287.

14. White RE, Calderwood MA, Whitehouse A. Generation and precise modification of a herpesvirus saimiri bacterial artificial chromosome demonstrates that the terminal repeats are required for both virus production and episomal persistence. J Gen Virol. 2003; 84 (Pt 12): 3393-403. DOI: 10.1099/vir.0.19387-0. PubMed PMID: 14645920

15. Hiller C, Wittmann S, Slavin S, Fickenscher H. Functional longterm thymidine kinase suicide gene expression in human $\mathrm{T}$ cells using a herpesvirus saimiri vector. Gene Ther. 2000; 7 (8): 66474. DOI: 10.1038/sj.gt.3301158. PubMed PMID: 10800089. 
16. Horton RM, Hunt HD, Ho SN, Pullen JK, Pease LR. Engineering hybrid genes without the use of restriction enzymes: gene splicing by overlap extension. Gene. 1989; 77 (1): 61-8. DOI: 10.1016/0378-1119(89)90359-4. PubMed PMID: 2744488.

17. Fukumoto Y, Obata Y, Ishibashi K, Tamura N, Kikuchi I, Aoyama K, et al. Cost-effective gene transfection by DNA compaction at $\mathrm{pH} 4.0$ using acidified, long shelf-life polyethylenimine. Cytotechnology. 2010; 62 (1): 73-82. DOI: 10.1007/s10616-0109259-z. PubMed PMID: 20309632.

18. Turrell SJ, Whitehouse A. Mutation of herpesvirus Saimiri ORF51 glycoprotein specifically targets infectivity to hepatocellular carcinoma cell lines. J Biomed Biotechnol. 2011; 2011: 785158. DOI: 10.1155/2011/785158. PubMed PMID: 21197456.

19. Duboise SM, Guo J, Desrosiers RC, Jung JU. Use of virion DNA as a cloning vector for the construction of mutant and recombinant herpesviruses. Proc Natl Acad Sci USA. 1996; 93 (21): 11389-94. DOI: 10.1073/pnas.93.21.11389. PubMed PMID: 8876145

20. White RE, Calderwood MA, Whitehouse A. Generation and

\section{References}

1. Davison AJ. Overview of classification. In: Arvin A, Campadelli-Fiume G, Mocarski E, Moore PS, Roizman B, Whitley R, et al., editors. Human Herpesviruses: Biology, Therapy and Immunoprophylaxis. Cambridge, 2007

2. Javier RT, Butel JS. The history of tumor virology. Cancer Res. 2008; 68 (19): 7693-706. DOI: 10.1158/0008-5472.CAN-083301. PubMed PMID: 18829521

3. Chang Y, Cesarman E, Pessin MS, Lee F, Culpepper J, Knowles DM, et al. Identification of herpesvirus-like DNA sequences in AIDSassociated Kaposi's sarcoma. Science. 1994; 266 (5192): 1865-9. DOI: 10.1126/science.7997879. PubMed PMID: 7997879.

4. Fu Z, Cannon MJ. Functional analysis of the CD4(+) T-cell response to Epstein-Barr virus: T-cell-mediated activation of resting B cells and induction of viral BZLF1 expression. J Virol. 2000; 74 (14): 6675-9. DOI: 10.1128/jvi.74.14.6675-6679.2000. PubMed PMID: 10864684.

5. Fickenscher $\mathrm{H}$, Fleckenstein $\mathrm{B}$. Herpesvirus saimiri. Philos Trans R Soc Lond B Biol Sci. 2001; 356 (1408): 545-67. DOI: 10.1098/ rstb.2000.0780. PubMed PMID: 11313011.

6. Biesinger B, Muller-Fleckenstein I, Simmer B, Lang G, Wittmann S, Platzer $E$, et al. Stable growth transformation of human $T$ lymphocytes by herpesvirus saimiri. Proc Natl Acad Sci USA 1992; 89 (7): 3116-9. DOI: 10.1073/pnas.89.7.3116. PubMed PMID: 1313581

7. Vogel B, Tennert K, Full F, Ensser A. Efficient generation of human natural killer cell lines by viral transformation. Leukemia. 2014; 28 (1): 192-5. DOI: 10.1038/leu.2013.188. PubMed PMID: 23787393.

8. Duboise SM, Guo J, Czajak S, Desrosiers RC, Jung JU. STP and Tip are essential for herpesvirus saimiri oncogenicity. J Virol. 1998; 72 (2): 1308-13. PubMed PMID: 9445031

9. Griffiths R, Whitehouse A. Herpesvirus saimiri episomal persistence is maintained via interaction between open reading frame 73 and the cellular chromosome-associated protein MeCP2. J Virol. 2007; 81 (8): 4021-32. DOI: 10.1128/JVI.02171-06. PubMed PMID: 17267510.

10. Verma SC, Robertson ES. ORF73 of herpesvirus Saimiri strain C488 tethers the viral genome to metaphase chromosomes and binds to cis-acting DNA sequences in the terminal repeats. J Virol. 2003; 77 (23): 12494-506. DOI: 10.1128/jvi.77.23.1249412506.2003. PubMed PMID: 14610173.

11. Knappe A, Feldmann G, Dittmer U, Meinl E, Nisslein T, Wittmann S, et al. Herpesvirus saimiri-transformed macaque $T$ cells are tolerated and do not cause lymphoma after autologous reinfusion. Blood. 2000; 95 (10): 3256-61. PubMed PMID: 10807797.

12. Menotti L, Avitabile E, Gatta V, Malatesta P, Petrovic B, Campadelli-Fiume G. HSV as A Platform for the Generation of Retargeted, Armed, and Reporter-Expressing Oncolytic Viruses. Viruses. 2018; 10 (7). DOI: 10.3390/v10070352. PubMed PMID: 29966356. precise modification of a herpesvirus saimiri bacterial artificial chromosome demonstrates that the terminal repeats are required for both virus production and episomal persistence. J Gen Virol. 2003; 84 (Pt 12): 3393-403. DOI: 10.1099/vir.0.19387-0 PubMed PMID: 14645920.

21. Collins CM, Medveczky MM, Lund T, Medveczky PG. The terminal repeats and latency-associated nuclear antigen of herpesvirus saimiri are essential for episomal persistence of the viral genome. J Gen Virol. 2002; 83 (Pt 9): 2269-78. DOI: 10.1099/0022-131783-9-2269. PubMed PMID: 12185282.

22. Ensser A, Thurau M, Wittmann S, Fickenscher $\mathrm{H}$. The genome of herpesvirus saimiri $\mathrm{C} 488$ which is capable of transforming human T cells. Virology. 2003; 314 (2): 471-87. DOI: 10.1016/s00426822(03)00449-5. PubMed PMID: 14554077.

23. Macnab S, White R, Hiscox J, Whitehouse A. Production of an infectious Herpesvirus saimiri-based episomally maintained amplicon system. J Biotechnol. 2008; 134 (3-4): 287-96. DOI: 10.1016/j.jbiotec.2008.01.012. PubMed PMID: 18328588.

13. Albrecht JC, Nicholas J, Biller D, Cameron KR, Biesinger B Newman $C$, et al. Primary structure of the herpesvirus saimin genome. J Virol. 1992; 66 (8): 5047-58. PubMed PMID: 1321287.

14. White RE, Calderwood MA, Whitehouse A. Generation and precise modification of a herpesvirus saimiri bacterial artificial chromosome demonstrates that the terminal repeats are required for both virus production and episomal persistence. J Gen Virol. 2003; 84 (Pt 12): 3393-403. DOI: 10.1099/vir.0.19387-0. PubMed PMID: 14645920.

15. Hiller C, Wittmann S, Slavin S, Fickenscher H. Functional longterm thymidine kinase suicide gene expression in human $\mathrm{T}$ cells using a herpesvirus saimiri vector. Gene Ther. 2000; 7 (8): 66474. DOI: 10.1038/sj.gt.3301158. PubMed PMID: 10800089.

16. Horton RM, Hunt HD, Ho SN, Pullen JK, Pease LR. Engineering hybrid genes without the use of restriction enzymes: gene splicing by overlap extension. Gene. 1989; 77 (1): 61-8. DOI: 10.1016/0378-1119(89)90359-4. PubMed PMID: 2744488.

17. Fukumoto Y, Obata Y, Ishibashi K, Tamura N, Kikuchi I, Aoyama K, et al. Cost-effective gene transfection by DNA compaction at $\mathrm{pH} 4.0$ using acidified, long shelf-life polyethylenimine. Cytotechnology. 2010; 62 (1): 73-82. DOI: 10.1007/s10616-0109259-z. PubMed PMID: 20309632

18. Turrell SJ, Whitehouse A. Mutation of herpesvirus Saimiri ORF51 glycoprotein specifically targets infectivity to hepatocellular carcinoma cell lines. J Biomed Biotechnol. 2011; 2011: 785158. DOI: 10.1155/2011/785158. PubMed PMID: 21197456

19. Duboise SM, Guo J, Desrosiers RC, Jung JU. Use of virion DNA as a cloning vector for the construction of mutant and recombinant herpesviruses. Proc Natl Acad Sci USA. 1996; 93 (21): 11389-94. DOI: 10.1073/pnas.93.21.11389. PubMed PMID: 8876145.

20. White RE, Calderwood MA, Whitehouse A. Generation and precise modification of a herpesvirus saimiri bacterial artificial chromosome demonstrates that the terminal repeats are required for both virus production and episomal persistence. J Gen Virol. 2003; 84 (Pt 12): 3393-403. DOI: 10.1099/vir.0.19387-0. PubMed PMID: 14645920.

21. Collins CM, Medveczky MM, Lund T, Medveczky PG. The terminal repeats and latency-associated nuclear antigen of herpesvirus saimiri are essential for episomal persistence of the viral genome. J Gen Virol. 2002; 83 (Pt 9): 2269-78. DOI: 10.1099/0022-131783-9-2269. PubMed PMID: 12185282.

22. Ensser A, Thurau M, Wittmann S, Fickenscher $\mathrm{H}$. The genome of herpesvirus saimiri $\mathrm{C} 488$ which is capable of transforming human T cells. Virology. 2003; 314 (2): 471-87. DOI: 10.1016/s0042 6822(03)00449-5. PubMed PMID: 14554077.

23. Macnab S, White R, Hiscox J, Whitehouse A. Production of an infectious Herpesvirus saimiri-based episomally maintained amplicon system. J Biotechnol. 2008; 134 (3-4): 287-96. DOl: 10.1016/j.jbiotec.2008.01.012. PubMed PMID: 18328588. 